\title{
CIRCULATION AND EXCHANGE AT THE CONTINENTAL SHELF AND SLOPE SEEP-II
}

DE92 013500

\author{
Final Report \\ for period May 1, 1989 - December 31, 1991
}

\author{
Robert W. Houghton \\ Hsien-Wang Ou
}

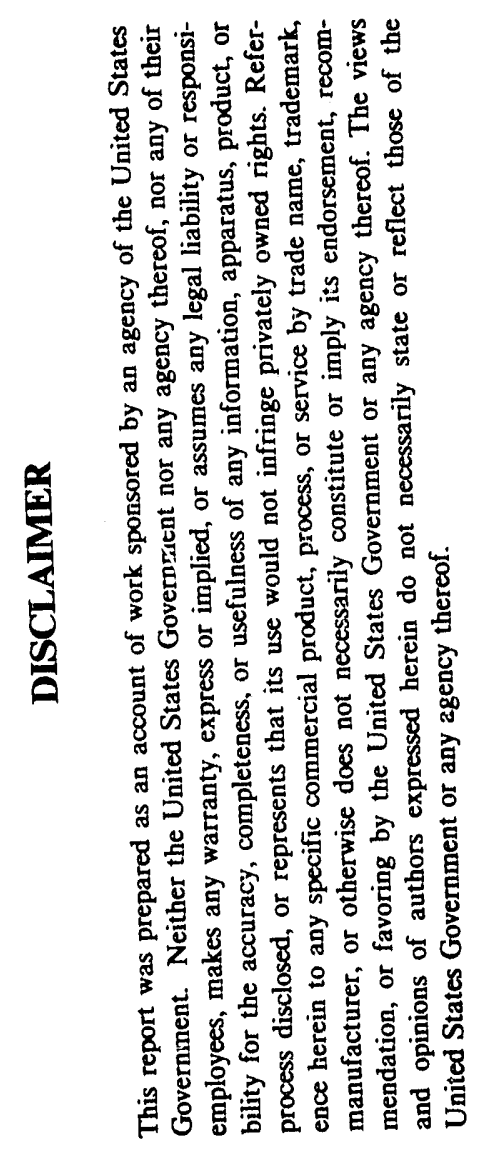

\author{
Lamont-Doherty Geological Observatory \\ of \\ Columbia University \\ Palisades, New York 10964
}

submitted to:
Division of Ecological Research
Office of Health and Environmental Research
U.S. Department of Energy

Contract No. DE-FG02-89E960818

APR 201992

This report was prepared as an account of work sponsored by the United States government. Neither the United States nor the Department of Energy, nor any of their employees, nor any of their contractors, subcontractors, or their employees, makes any warranty, express or implied, or assumes any legal liability or responsibility for the accur acy, completeness, or usefulness of any information, apparatus, product or process disclosed or represents that its use would not infringe privately-owned rights. 


\section{ABSTRACT}

This project was a component of the SEEP-Ii program. It contributed to the instrumentation of the SEEP-II moored array to the processing and analysis of the time-series data of water temperature and currents, and to a theoretical modeling study of the circulation on the continental margin.

Analysis of the structure, motion of the shelf-slope water front at the shelfbreak, and crossshelf eddy heat flux calculations yield the following results. During the winter and spring the inclination of the frontal boundary and the vertical velocity shear, when averaged over periods greater than a week, approximately satisfy the Margules' Equation. Associated with the locally wind-driven cross-shelf excursions $(\sim 20 \mathrm{~km})$ of the foot of the front are vertical displacements of the frontal boundary due to vorticity constraints imposed by the bottom topography. Some of the smaller scale frontal motions suggest a wave like disturbance propagating southward along the continental margin. In April 1988 the most severe wind event recorded during SEEP-II displaced the foot of the front out into the upper slope region and injected shelf water into the interior of the slope water column.

On the mid-shelf cross-shelf eddy heat fluxes are negligible as temperature variations and cross-shelf velocities are in quadrature. At the shelfbreak, however, depth averaged heat fluxes approximately $4 \times 10^{6} \mathrm{~W} / \mathrm{m}$ are onshore, significantly different from zero and comparable to the exchange estimated by Fairbanks using 180 tracer data. In the winter and spring the eddy flux is greatest near the frontal boundary in the lower water column and dominated by a few large exchange events. In the summer the subtidal eddy flux is greatest just below the seasonal pycnocline in the upper water column with a peak in the 5-11 day band that suggests a contribution from frontal instabilities.

Bottom Eulerian mean velocities are $1-2 \times 10^{-2} \mathrm{~m} / \mathrm{s}$ offshore over the shelf and slope. Measured eddy fluxes are adequate to achieve the advective-diffusive balance required to maintain the frontal position in steady state.

A second component of this project was a theoretical study of the interaction of the Gulf Stream with the continental margin north of Cape Hatteras. The model shows how the topographic influence on the local vorticity balance leads to back-folding filaments of Gulf Stream water and to the Slope Sea gyre circulation. 


\section{PROJECT REPORT}

This project consists of two parts each of which is a contribution to the SEEP-II program. The first is data processing and analysis conducted by R.W. Houghton. The second is theoretical modeling studies of the Gulf Stream's interaction with topography north of Cape Hatteras by H.W. Ou. The report of each part is presented in sequence.

\section{Data Processing and Analysis}

We were responsible for nearly half of the current meters and thermistor chains that were deployed in the SEEP-II moored array on the continental margin off the Delmarva peninsula. Data tapes derived from three deployments of the instruments in this array were processed. The data were edited and then distributed to other SEEP-II P.I.s.

For the last 2 years of this project we have concentrated on an analysis of the combined SEEP-II temperature and current data. The objective of this analysis was to characterize the structure and motion of the shelfbreak front. A further objective was to calculate the heat flux across the frontal boundary in order to assess the magnitude of and the processes responsible for this shelf-slope exchange. The results of this analysis are described in detail in the manuscript that accompanies this report and so they are not repeated here.

The SEEP-II program in general and our project in particular have contributed to a greater understanding of the kinematics and dynamics of shelfbreak motion and exchange processes. We have shown that the eddy heat flux is smaller though of the same order of magnitude as in coastal upwelling regimes and is comparable to previous estimates using tracer distribution. Much of the flux is derived from lo'w frequency wind driven motion of the shelfbreak front. The flux is modulated seasonally with a vertical distribution that changes in response to the changes in the stratification. During the winter exchange is primarily at the foot of the front while in the summer it is greatest at mid-depth just below the pycnocline on density surfaces connecting shelf and slope water regions. This pattern has important implications to our understanding of the coastal ecosystem. The springtime heat flux and the temperature-nitrate regression implies an onshore nitrate flux of $900 \mu \mathrm{mol} / \mathrm{s}$ per meter of alongshore distance which could support roughly $10 \%$ of the spring carbon production that is thought to be exported from the shelf. In the summer the nutrient flux to the euphotic zone at the front appears to come from deep shelf water although we are unable to quantify this flux. 
The most important recent advance in our understanding of the dynamics that contributes to the frontogenesis at the shelfbreak is the recent model study by Gawarkiewicz and Chapman (1992). They explore the influence of the bottom boundary layer flow on the shelf circulation. The influence is profound. They find convergence in the bottom offshore flow at the shelfbreak which is intensified by stratification. The result is strong frontogenesis at the shelf break where offshore flow leaves the boundary layer and travels up along density surfaces of the frontal boundary. This completely reverses the flow patterns of surface convergence and onshore bottom flow that had been previousiy derived from quasi-geostrophic adjustment models.

Our analysis of SEEP-II data lends credence to these new ideas. Bottom flow near the shelfbreak is offshore. Although we show that with the measured eddy flux there is an approximate advective-diffusive balance at the foot of the front, there is evidence of offshore flow into the interior of the water column. Understanding the full implications of this new paradigm for the shelf ecosystem is an objective worthy of continued research in the future.

\section{Modeling Studies}

A theoretical model was developed to examine the interaction of the Gulf Stream with the shelf and slope water off the Middle Atlantic states, with the intention of interpreting and understanding the SEEP observations. The model utilizes similarity solutions which facilitates solutions even when the jet is strong and the physics is nonlinear. Through the model solutions, we have suggested physical mechanisms that can account for the varied form of Gulf Stream interaction with the ambient water, including its shoreward intrusion off Cape Hatteras in the form of back-folding filaments, its entrainment of shelf water along its northern edge and its entrainment of nutrients across the jet axis. The model also provides a probable explanation of the presence of Slope Sea gyre and the mean southwestward flow over the shelf. The research has resulted in a manuscript entitled "On the Interaction of an Oceanic Jet with a Continental Boundary" submitted to Journal of Physical Oceanography and presently under review. A copy of the manuscript is appended with this report.

\section{Publications}

The following are manuscripts derived from this project all of which, except for H.W. Ou, are submitted for inclusion in a special SEEP-II issue of Continental Shelf Research. 
Flagg, C.N., R.W. Houghton, and L.T. Pietrafesa, 1992. Summertime thermocline and subthermocline cross-frontal intrusions in the Mid-Atlantic Bight. Continental Shelf Res. (Submitted).

Houghton, R.W., C.N. Flagg and L.J. Pietrafesa, 1991. Shelf slope water frontal structure, motion, and eddy heat flux in the Southern Middle Atlantic Bight. (submitted).

Janowitz, G.S., L.J. Pietrafesa and R.W. Houghton, 1992. Alongshore variations in coastal sea level in the Middle Atlantic Bight. Continental Shelf Res. (submitted).

Ou, H-W, 1992. On the interaction of an oceanic jet with a continental boundary. J. Phys.Oceanogr. (submitted)

Pietrafesa, L.J., J.M. Morrison, M.P. McCanr, R.W. Houghton, J. Churchill, and J. Janowitz (1991). Water mass linkages between the Middle and South Atlantic Bights. Continental Shelf Res. (submitted).

Pietrafesa, L.J., R.W. Houghton and C.N. Flagg (1992). Overview of circulation during SEEPII. Continental Shelf Res. (submitted).

Pietrafesa, L.J., C.D. Wirick, G.S. Janowitz, F.E. Hoge, R.W. Houghton and C.N. Flagg, 1992. Fluorometer, near surface currents and airborne Lidar: a case study. Continental Shelf Res. (submitted).

Show, P-T, L.J. Pietrafesa, C.N. Flagg, R.W. Houghton and K-H Su, 1992. Low frequency oscillations on the outer shelf. Continental Shelf Res. (submitted). 

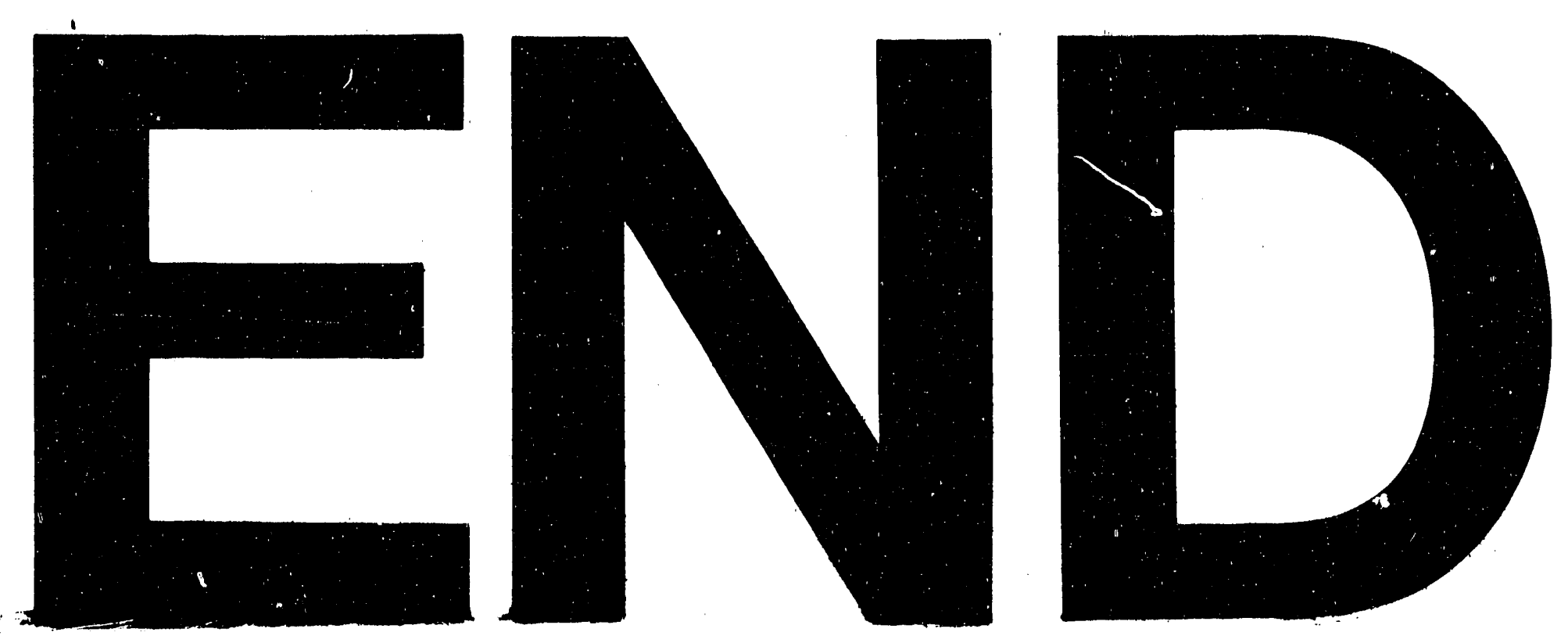

\section{$\ldots$}
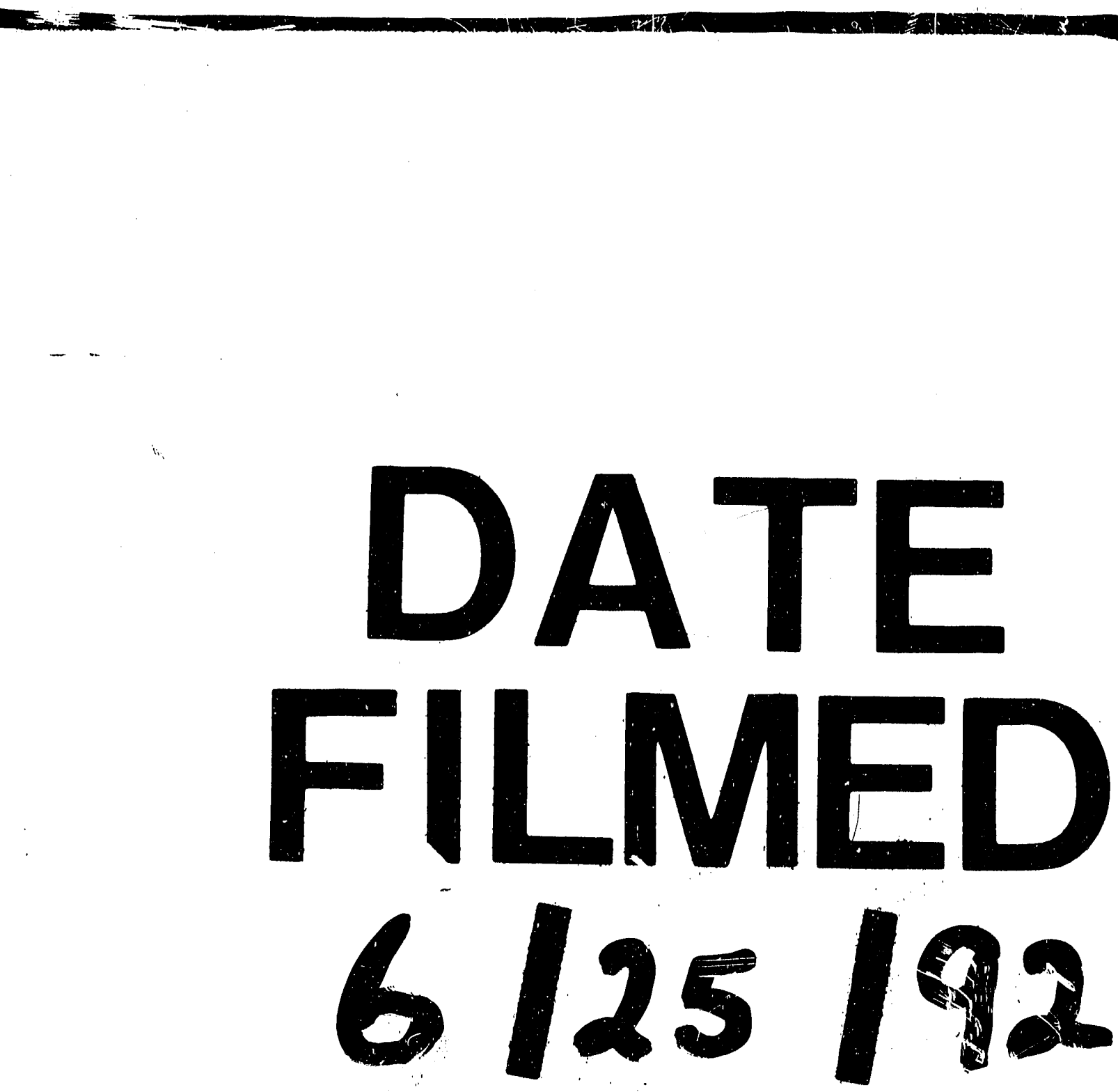
